\title{
GEOGRAFÍAS, ENTRAMADOS Y RE-EXISTENCIAS EN LAS POBLACIONES NEGRAS DEL VALLE DEL PATÍA Y EL PACÍFICO SUR COLOMBIANO
}

\author{
GEOGRAPHIES, ASSEMBLAGE AND RE-EXISTENCES IN THE BLACK \\ POPULATIONS OF THE PATÍA VALLEY AND THE COLOMBIAN SOUTH \\ PACIFIC
}

Yilver Mosquera-Vallejo ${ }^{1}$ y Javier Tobar ${ }^{2}$

\begin{abstract}
Este artículo ofrece un recorrido de los conceptos "identidad", “diferencia cultural” y "lugar", expuestos para evidenciar cómo han sido entendidos desde la antropología y la geografía humana. En este marco conceptual, el objetivo del artículo examina las geografías, los entramados y las re-existencias que se despliegan en las poblaciones negras del Valle del Patía y el Pacífico sur colombiano, a la luz de la evidencia sociohistórica y geográfica desde 1993 hasta el año 2020. La estrategia analítica consistió en identificar, a partir de los trabajos publicados en las últimas tres décadas, los procesos históricos, las re-existencias y las formas en que discursivamente han sido producidos estos territorios. Se encontró que mientras el Pacífico sur ha estado atravesado por diferentes ciclos extractivistas, desde la época Colonial hasta la actualidad, y en las últimas tres décadas por un proceso que coproduce etnización y biodiversidad, el Valle del Patía, por su experiencia colonial, está articulado a prácticas de cimarronaje que se han sedimentado en la vida cotidiana, dando lugar a re-existencias. Finalmente, se establece que ambos espacios han sido objeto de una violencia constitutiva que ha producido territorios aterrorizados.
\end{abstract}

Palabras claves: lugar, re-existencias, Pacífico sur, Valle del Patía.

This paper offers an overview of the concepts of identity, cultural difference, and place, showing how they have been understood by anthropology and human geography. In this context, it aims to examine the geographies, networks and re-existences that have unfolded among the black populations of the Patía Valley and the Colombian South Pacific in the light of socio-historical and geographical evidence from 1993 to 2020. Using works published in the last three decades, our strategy consisted in identifying the historical processes, re-existences, and the ways in which these territories have been discursively produced. While the South Pacific has been traversed by different extractivist cycles from colonial times to the present, and in the last three decades by a process that co-produces ethnicity and biodiversity, we found, due to its colonial experience, that the Patia Valley is tied to maroon practices that have crystallized in everyday life, thus giving rise to re-existence. Finally, we establish that both spaces have been the object of constitutive violence that has produced terrorized lands.

Key words: Place, Patía valley, South Pacific, re-existences.

En las últimas tres décadas los estudios afrocolombianos han consolidado una amplia y fructífera producción académica llevada a cabo a partir de diferentes enfoques teóricos, dando lugar a una heterogeneidad de problemáticas que han sido objeto de continuas disquisiciones en las ciencias sociales. Este campo plural marcó un giro hacia el multiculturalismo a partir de la promulgación de la Constitución Política de 1991 en Colombia, en particular, por el artículo transitorio 55 (A.T 55) que dio origen a la Ley 70 de 1993 o de comunidades negras y sus decretos reglamentarios; un factor a determinar para el análisis de las intervenciones en la construcción de lo negro y de sus territorios como sujetos de inteligibilidad política, que ha servido de pivote para la consolidación y eclosión de investigaciones sobre poblaciones negras en las últimas tres décadas (Velandia y Restrepo 2017).

Aunque este artículo se inscribe dentro del campo de los estudios afrocolombianos, se hace con una perspectiva interdisciplinaria, particularmente desde la antropología y geografía humana.

\footnotetext{
Instituto de Geografía, Pontificia Universidad Católica, Santiago, Chile. yamosquera@uc.cl

2 Universidad del Cauca, Popayán, Colombia. javo@unicauca.edu.co
} 
El proceso genealógico definido por este trabajo se basa en la cartografía esquematizada por Velandia y Restrepo (2017) acerca de los estudios afrocolombianos desde la década de 1950 hasta la actualidad Estos autores destacan cuatro momentos relevantes del campo en diferentes periodos históricos: "pioneros (década del cincuenta y parte de los años sesenta), emergencia (segunda mitad de los años sesenta y la década de los ochenta), consolidación (década del noventa) y eclosión (desde comienzos del milenio hasta el presente)" (Velandia y Restrepo 2017:163-164), siendo estos dos últimos los momentos que constituyeron los soportes para la evidencia sociohistórica y geográfica de los espacios estudiados. En tal sentido, el propósito de este trabajo consiste en examinar las geografías, los entramados y las reexistencias que se despliegan en las poblaciones negras del Pacífico sur y Valle del Patía (al suroccidente de Colombia), a la luz de la evidencia sociohistórica y geográfica desde 1993 hasta el 2020.

Metodológicamente, se plantea una discusión teórica que articula perspectivas de la diferencia cultural y las geografías del lugar. Con ello se busca establecer puentes teóricos y sustantivos entre la antropología y la geografía humana, lo cual permite elaborar una síntesis de trabajos que han abordado aspectos relacionados con la historicidad y territorialidad en el Pacífico sur y Valle del Patía. Esto conduce a establecer una interpretación crítica de las modalidades y trayectorias bajo las cuales re-existen, así como se entraman, hibridizan y encuentran los procesos históricos y territoriales en los ámbitos estudiados.

El artículo está organizado de la siguiente manera: a la introducción le sigue el acápite sobre diferencia cultural y geografías del lugar, el cual, en primera instancia, examina las categorías de identidad y diferencia. En segunda instancia, las geografías del lugar se desarrollan a partir de las nociones de lugar de encuentro e hibridez. A continuación es descrito el Patía y el Pacífico sur como ámbitos geográficos, y se realiza una aproximación de las trayectorias históricas de estos lugares. De esta forma se hicieron evidentes las diferencias y similitudes histórico-espaciales entre estas dos zonas. Ello sirvió de sustento para analizar en el siguiente acápite, con base en la evidencia sociohistórica y geográfica recopilada de un trabajo de síntesis, las geografías, los entramados y las re-existencias en el Pacifico sur y Valle del Patía. Por último, las reflexiones finales articularon interpretaciones sobre las violencias que se han consolidado en los últimos años en estos ámbitos geográficos.

\section{Diferencia Cultural y Geografías del Lugar}

La identidad no debe ser pensada como una idea y sensación de seguir siendo lo mismo a través del tiempo (Wade 2002). Al contrario, identidad y diferencia sugieren la idea de contraste, pues se trata de una percepción y un relacionamiento del yo y del otro, que constituye un complejo movimiento de articulaciones situacionales; fenómeno que a su vez cobra sus sentidos a partir de diversas redes, acciones y movimientos, de tal suerte que identidad y diferencia transcurren por diferentes terrenos existenciales, pues son procesos y devenires surcados por vivencias y representaciones permanentemente condicionadas $\mathrm{y}$ transformadas.

Así, la identidad y diferencia son producidas en ámbitos históricos, geográficos y sociales, por supuesto, bajo diversas relaciones de poder y de desigualdad, en tanto las identidades "no solo se refieren a la diferencia, sino también a la desigualdad y a la dominación" (Restrepo 2007:27). Son más un producto de la marcación de la diferencia y la exclusión que el signo de una unidad auténtica (Hall 2003), y se establecen mediante actos repetidos de representación de rasgos que son observados e indicados como diferentes por unos sujetos en la vida cotidiana (Wade 2002).

La identidad está articulada con prácticas de dominación como el nacionalismo, racismo y colonialismo. En este caso, por ejemplo, "la identificación nunca es la afirmación de una identidad dada, nunca una profecía autocumplida: siempre es la producción de una imagen de identidad y la transformación del sujeto al asumir esa imagen" (Bhabha 2002:66). Homi Bhabha propone una lectura crítica de la representación de la identidad, la historia y la cultura conducente a interrumpir las dicotomías impuestas por la metafísica occidental. A propósito de la noción de cultura, Bhabha realiza un desplazamiento que consiste en entender lo cultural no como objeto epistemológico, sino como lugar de enunciación (Bhabha 2002). Para este autor la cultura como epistemología se concentra en la función e intención que tiende hacia un reflejo de su objeto empírico que la encierra en el círculo hermenéutico, a manera de una simple descripción de elementos culturales de una totalidad. Por otro lado, en tanto sitio 
enunciatorio, la cultura abre posibilidades para otros tiempos y espacios narrativos distintos, que se alejan $\mathrm{y}$ cuestionan las posiciones binarias, agenciando otras estrategias discursivas liberadoras o emancipatorias.

En este mismo sentido se advierte la distinción entre diversidad y diferencia cultural. Mientras la primera es reflejo de una idea epistemológica, la segunda hace referencia a la cultura entendida como lugar de enunciación, si bien "la diversidad cultural es objeto epistemológico (la cultura como objeto de conocimiento empírico), mientras que la diferencia cultural es el proceso de enunciación de cultura como 'cognoscible', autoritativa (authoritative), adecuada a la construcción de sistemas e identificación cultural" (Bhabha 2002:54).

Lo que Bhabha pone en tela de juicio con esta diferenciación es precisamente aquella retórica antropológica que representa al Otro desde la cultura, a modo de un ente único, inmaculado y autocontenido. Frente a esto, el autor señala la existencia de signos que construyen historias e identidades en la diferencia cultural, que no solo difieren en contenidos sino que a menudo producen sistemas incompatibles de significación y comprometen formas distintas de la subjetividad social. Es así que propone la idea de la diferencia como inconmensurabilidad cultural, y no la noción consensual etnocéntrica de la visión pluralística de la diversidad cultural, valga recordar, propuesta por la ética liberal.

En esta perspectiva, Bhabha ve la necesidad de develar la relación y la causalidad que vinculan la unicidad de relato con el poder, y a la historia con la escritura y la representación, en tanto poder y verdad. Por consiguiente, lo que pone en tela de juicio, a través de esta relación, es precisamente el plano de la representación y la significación en el campo político. En esta dirección, su interés se orienta a observar la relación que tienen la significación, los discursos y el poder, con la discriminación de la diferencia.

$\mathrm{El}$ autor indica que estamos en un más allá, en un lugar que perturba la dirección, en un espacio entremedio donde se inician nuevos signos de identidad. En consecuencia, identidad y diferencia se ubican en la emergencia de los intersticios, en un espacio liminal en el que la articulación social de la diferencia "es una compleja negociación en marcha que busca autorizar los híbridos que emergen en momentos de transformación histórica" (Bhabha 2002:18-19). De acuerdo con esto, "hay unas prácticas de hibridación y traducción mezclando todo el tiempo lo que ha querido separarse" (Restrepo 2011:311). Por su parte, Haesbaert enseña que cualquier interpretación que se realice acerca de la hibridación, es necesario historizarla y geografizarla dado que "ello permitirá reconocer los diferentes sujetos que la producen y los contextos geopolíticos en los que se realiza y circula su debate" (Haesbaert 2011:55-56).

\section{Las geografías del lugar}

La modernidad como arquitectura del saber ha definido formas de entender la realidad a partir de entes separados, tales como las dualidades sociedad-naturaleza, espacio-tiempo, naturalezacultura. Asimismo, cierta perspectiva mediante la cual se conceptualiza la modernidad introduce "la noción de 'Hombre' como el fundamento de todo conocimiento y orden en el mundo, separado de lo natural y lo divino" (Escobar 2003:56). En este encuadre, la modernidad se representa como "una lucha permanente en curso por definir los reales términos de las articulaciones del tiempo y el espacio, de la presencia y el cambio, las estructuras duraderas y la experiencia diaria" (Escobar 2010:341). A su vez, la modernidad desde el pensamiento crítico se lee como "una manifestación del eurocentrismo, de la imposición de sus particularismos como unos falsos universalismos que obliteran y subsumen las más disimiles expresiones de la diferencia (Restrepo 2011:127).

Posiblemente, quien más ha avanzado en las críticas a la modernidad es el teórico Bruno Latour. Este autor sostiene que lo "moderno" designa un conjunto de prácticas de purificación que "crea dos zonas ontológicas por completo distintas, la de los humanos, por un lado, la de los no humanos por el otro" (Latour 2008:28). Sin embargo, hay otras prácticas que “crea[n] por 'traducción' mezclas entre géneros de seres totalmente nuevos, híbridos de naturaleza y cultura" (Latour 2008:28).

La geografía como saber moderno no escapó a las distinciones analíticas de este periodo histórico. Sobre lo anterior, el geógrafo Milton Santos señalaba que "vivimos con una noción de territorio heredada de la modernidad incompleta y de su legado de conceptos puros, tantas veces atravesando los siglos prácticamente intocados" (Santos 1994:15). De esta forma, los conceptos puros, heredados de la modernidad incompleta, ya no son útiles para ayudarnos a pensar el presente.

Según lo anterior, el territorio debería ser pensado en su forma impura o como un híbrido (Moraes 2014). 
El mismo Santos, en relación con el concepto de espacio geográfico, señalaba que sería "un resultado de la inseparabilidad entre sistemas de objetos y sistemas de acciones" (Santos 2000:84); es decir, un híbrido. No está de más destacar que esta idea se enmarca en un debate teórico más amplio denominado "giro espacial". No obstante, para articular estas geografías del lugar, con el contrapunteo de la hibridez (Santos 2000), nos interesa conectar algunas inquietudes de Escobar (2010) con relación al lugar y la perspectiva de Massey sobre el mismo. De este modo, si partimos de una analítica que entiende el espacio desde una perspectiva híbrida, el lugar, al constituir una categoría de aquel, podríamos pensarlo como un híbrido.

El lugar constituye un nodo de articulaciones, tensiones, intercambios, contradicciones que se enredan. De hecho, Doreen Massey sostiene que "la especificidad de cada lugar es el resultado de la mezcla distinta de todas las relaciones, prácticas, intercambios, etc., que se entrelazan dentro de este nodo y es producto también de lo que se desarrolle como resultado de este entrelazamiento" (Massey 2004:79). A este respecto Escobar se preguntaba: “¿Puede uno reinterpretar los lugares como vinculándose para constituir redes, espacios desterritorializados, e incluso rizomas?" (Escobar 2000:69). Precisamente en esta dirección apunta el sentido global del lugar (Massey 2012), a diferencia de:

Pensar los lugares como áreas contenidas dentro de unos límites, podemos imaginarlos como momentos articulados en redes de relaciones e interpretaciones sociales en los que una gran proporción de estas relaciones, experiencias e interpretaciones están construidas a una escala mucho mayor que la que define en aquel momento el sitio mismo, sea una calle, una región o incluso un continente (Massey 2012:126).

El lugar no debe ser entendido como un enclave cerrado, ahistórico, autocontenido. Lejos de representar cerramientos, el lugar deviene "nodo de encuentro, como negociación constante, como hibridismo ineludible" (Massey 2004:80). La mediación que hace posible el lugar de encuentro es un conjunto de prácticas espaciales y relaciones económicas, sociales, ecológicas y culturales que producen, de forma diferenciada, múltiples lenguajes de diferenciación territorial, histórica, cultural, epistémica y ecológica. Estas prácticas y relaciones constituyen, a su vez, una serie de precondiciones desde las cuales se agencian entramados e hibridismos en espacios locales. Sobre estas cuestiones giran las siguientes reflexiones.

\section{EI Valle del Patía y la llanura del Pacífico (Figura 1)}

El Valle del Patía está localizado entre el sur del departamento del Cauca y en el norte del departamento de Nariño, en medio de las cordilleras central y occidental que forman los Andes intertropicales en Colombia. Su vegetación corresponde a ecosistemas de bosque seco tropical, distribuidos en formaciones boscosas riparias. Si bien se trata de una zona con abundante biodiversidad, si se juzga a partir de las clasificaciones de flora (Fernández y Fernández 1992), no ha sido conceptualizada ni representada desde la exuberancia de sus paisajes naturales. Lejos de concebirse como un espacio biodiverso, el Patía se ha enunciado históricamente como un espacio caluroso, ardiente, peligroso y desértico.

En este paisaje, entre seco, verde y frondoso, fue que se asentaron poblaciones negras que darían lugar a la formación de la sociedad patiana, la cual se formó, por una parte, con cimarrones que vivieron en el Palenque del "Castigo" luego de huir de las minas de Barbacoas e Iscuandé y de algunas haciendas del Valle del Cauca, durante los siglos XVII y primeras décadas del XVIII. Por otra parte, se constituyeron a partir de las poblaciones esclavizadas que fueron incorporadas en el desarrollo de diversas actividades en las haciendas y minas instaladas en el área hacia el siglo XVIII (Zuluaga 1993).

Este valle ha sido objeto de distintas formas de intervención llevadas a cabo por diferentes actores sociales, lo que ha terminado por configurar parte de la historia territorial de estas planicies. La primera intervención se vincula al asentamiento de las poblaciones negras desde la época Colonial, el segundo momento está dado por el quiebre identificado a partir de la construcción de la carretera panamericana en 1930, y el tercero se produce en la década de 1960 y marca el proceso genealógico con que se inicia la modernización en el Valle del Patía (Albán 2015).

La llanura del Pacífico se caracteriza por una altísima pluviosidad y exuberante vegetación (Escobar 2010; Restrepo 2013a). Esta región se encuentra subdividida en dos zonas: el andén aluvial o zona 


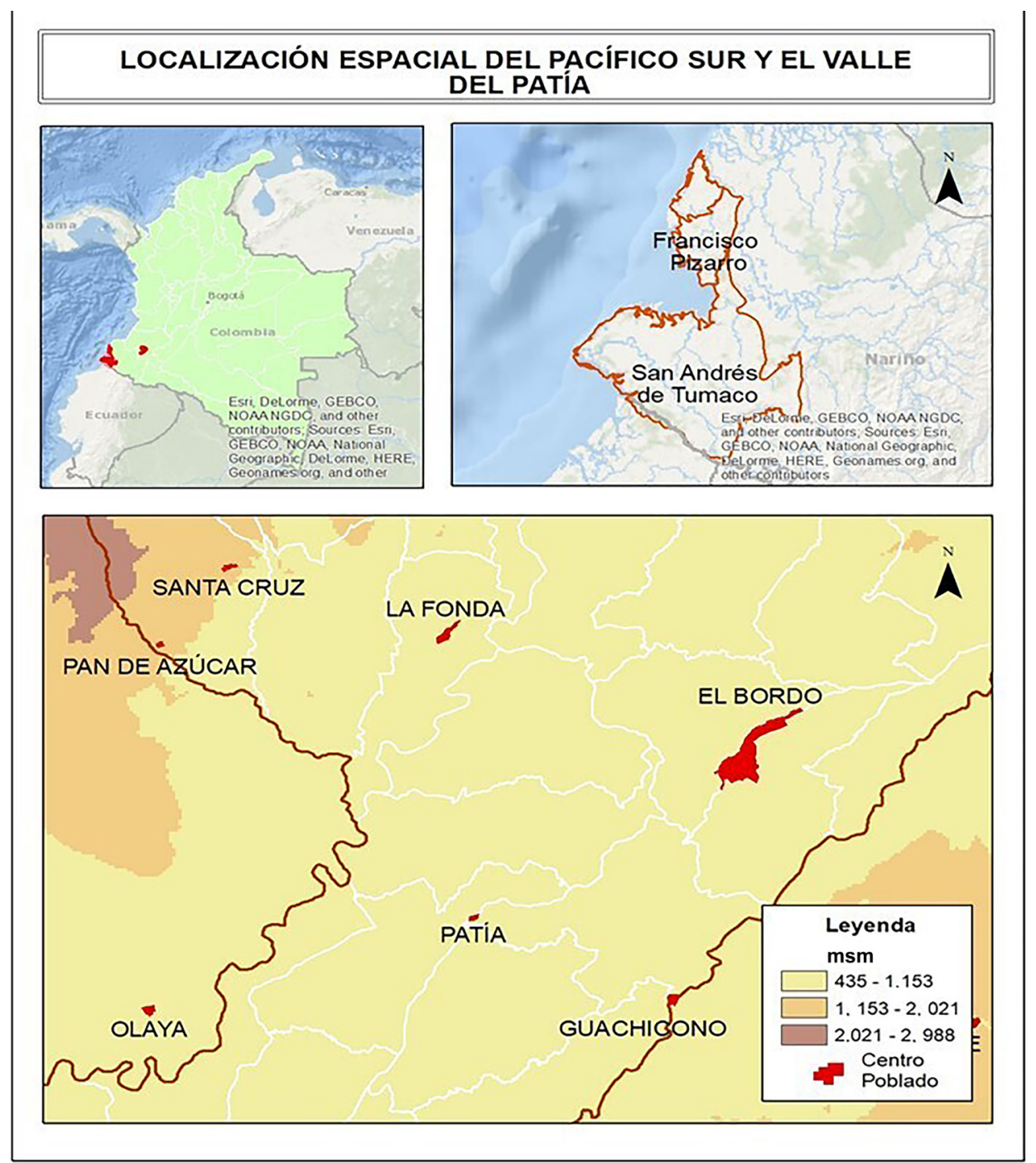

Figura 1. Localización del área de estudio. Fuente: Elaboración propia.

Study area location map. Source: developed by the authors.

de mangle y la llanura del bosque húmedo, la que se extiende hasta las estribaciones de la cordillera occidental andina. Además, está conformada por numerosos ríos que se caracterizan por ser de tramos cortos, con excepción del Río Patía, que posee un curso relativamente largo y de alto caudal.

El Pacífico sur ha sido también objeto de diferentes modelos de intervención que han definido distintas formas de apropiación espacial. En la época Colonial se destaca un patrón centrado en las "cuadrillas seminómadas y los reales de minas" (Restrepo 2016:190). Este modelo, identificado en la clasificación establecida por Almario García (2009) como región y economía política, decayó "por la disolución de la esclavitud y el declive de la producción de oro, con lo cual deviene marginal al proyecto nacional, que sin embargo permite la vigorosa presencia de las comunidades negras e indígenas" (Almario García 2009:112). Como consecuencia de la caída del modelo económico basado en la extracción de oro y el trabajo esclavo, el "Pacífico sur quedó marginado del resto del país colombiano" (Almario García 2013:196).

Diferentes formas de conexión con el proyecto nacional se establecieron en el Pacífico sur. Así, durante gran parte del siglo XIX la región vivió diferentes tensiones producto de las guerras de independencia, $\mathrm{y}$ constantes reconfiguraciones que se dan en el marco de las fracturas territoriales de la antigua gobernación 
de Popayán (Almario García 2009). En esta época la región sostuvo redes comerciales entre Colombia y Ecuador, pues mantuvo la dependencia de los circuitos de mercado y de suministros entre las ciudades andinas del sur del país y Quito (Almario García 2009). obernación de Popayán (Almario García 2009). En esta época la región sostuvo redes comerciales entre Colombia y Ecuador, pues mantuvo la dependencia de los circuitos de mercado y de suministros entre las ciudades andinas del sur del país y Quito (Almario García 2009).

En el siglo XIX se consolidó una población libre, de gentes "dedicadas no sólo a las actividades mineras sino, también, a actividades agrícolas, de pesca o de cacería, consolidando tempranos poblados en los ríos o en las costas" (Restrepo 2016:199). Asimismo, desde mediados del "siglo XX esta configuración espacial de asentamientos dispersos empezó a cambiar con la consolidación de centros urbanos" (Restrepo 2016:202). Ello dio lugar a la fundación y consolidación de los municipios de Tumaco, Barbacoas, Mosquera, Olaya Herrera, Francisco Pizarro, el Charco, La Tola, Santa Bárbara y Roberto Payan, donde actualmente se asientan las comunidades negras del Pacífico sur.

Este fenómeno es resultado de un proceso histórico, propio del sistema mundial moderno/ colonial, en el que ha imperado economías extractivas como la explotación de madera. Sin embargo, los desplazamientos poblacionales aún persisten como consecuencia de problemas de orden ecológico, económico y político. En síntesis, para las poblaciones negras de esta región del país, el entramar sus territorios ha implicado tanto el desarraigo y la apropiación como la constante reconstrucción de sus lugares de vida y de su diferencia cultural, todo ello en medio del conflicto y de múltiples formas de violencia.

\section{Lugar, entramado y re-existencias en el Pacífico sur y Valle del Patía}

Antropólogos, geógrafos e historiadores han demostrado elocuentemente las formas en que el Valle del Patía y el Pacífico sur colombiano se hacen lugar de encuentro, entramado territorial y de re-existencia. Sobre ambos espacios destacamos el trabajo de los autores que sistemáticamente han aportado al entendimiento de estos ámbitos geográficos desde los tópicos estudiados.

En Territorios de diferencia Escobar cuestiona la incorporación del Pacífico a la modernidad, la nación y el globo, pues en términos históricos este fue imaginado como un lugar recóndito, distante, de frontera, ubicado en los confines de la nación (Escobar 2010). Si bien es cierto que el Pacífico continúa siendo imaginado, intervenido y proyectado desde los supuestos de un lugar atrasado, también es verdad, como ha argumentado Eduardo Restrepo, que en las últimas tres décadas "la región del Pacífico colombiano constituye un proverbial espacio de biodiversidad es una verdad de a puño entre algunos académicos, funcionarios y, cada vez más, para sus mismos habitantes" (Restrepo 2013a:173). De tal suerte que no es extraño que hoy en día "el imaginario de la biodiversidad del Chocó biogeográfico haya sido decantado hasta tal punto que aparezcan libros de lujo dedicados al 'asombro de tal exuberancia de la naturaleza"” (Restrepo 2013b:212).

Es desde el encuadre de giro hacia lo biodiverso que se enmarca el trabajo investigativo de Escobar (2010). A partir de su ejercicio etnográfico en el Pacífico, este autor articula las categorías de modernidades alternativas y alternativas a la modernidad. La primera parte de un descentramiento de la idea de modernidad, como una experiencia europea, a una pluralización de la modernidad. Esto se evidenciaría mediante una "negociación incesante de la modernidad en relación con la contra-labor que los grupos locales necesariamente efectúan sobre los elementos del desarrollo y la modernidad, y hacia formas de modernidad más auto-orientadas" (Escobar 2010:188).

Esto supone que los territorios reciben y negocian la modernidad de forma diferenciada, y ello se articula a partir de prácticas basadas en el lugar, mientras que alternativas a la modernidad representan una propuesta más radical. Estos procesos realizados desde los movimientos sociales constituyen un "proyecto más radical y visionario [para] redefinir y reconstruir mundos locales y regionales desde la perspectiva de las prácticas de la diferencia cultural, económica y ecológica, siguiendo una lógica de la red y en contextos de poder" (Escobar 2010:188).

Estas conceptualizaciones de la modernidad, enlazadas mediante el trabajo etnográfico de Arturo Escobar en el Pacífico, adquieren sentido en la idea que entiende el Pacífico como un discurso, en la medida que ha sido producido históricamente, en contraposición a los centros de la nación, es decir, como región de frontera; y de manera simultánea, la producción de este ámbito espacial se va dando a través de procesos que se despliegan en lo local y se globalizan. Precisamente, la globalización supone 
varias cosas: es un proceso económico, cultural e histórico, pero principalmente se trata de un proceso geográfico que implica la conexión en mayor medida y de diferentes formas de unos lugares con otros.

Una de las modalidades a partir de las cuales se ha insertado el Pacífico, y al mismo tiempo deslugarizado vinculándose a las dinámicas de la economía-mundo, ha sido mediante los ciclos extractivistas. Es el caso de la industria maderera, que se inició en la década de 1940 y se constituyó en una de las actividades económico-productivas más relevantes de la región (Leal y Restrepo 2003).

Sobre este proceso los autores constatan que a mediados del siglo XX se inició el apogeo de la extracción maderera. Inicialmente se caracterizó "por la intervención de capitales extranjeros, la innovación tecnológica, la extensión frente a la extracción, la creciente importancia de la actividad maderera para la zona, y la consolidación de un grupo de corteros y asalariados dependientes de la industria" (Leal y Restrepo 2003:49). La extracción maderera, desde la perspectiva etnográfica planteada por los autores, permite entender de qué manera y por qué el Pacífico se ha relacionado con "el resto del mundo y, por otra parte, es un referente necesario para comprender aspectos cruciales de la configuración de las dinámicas locales y las transformaciones ocurridas allí en la segunda mitad del siglo XX" (Leal y Restrepo 2003:19).

Inspirado en la tesis de Henri Lefebvre acerca del proceso de producción de espacio, Oslender elabora parte de su trabajo sobre el Pacífico. La idea de producción del espacio se entiende a partir del nexo entre las prácticas espaciales, las representaciones espaciales y los espacios de representación (Oslender 2002). Sin embargo, para hacer un análisis detallado del movimiento social afrocolombiano, como mediación analítica, Oslender utiliza el concepto de lugar desarrollado por John Agnew. así el concepto de lugar se "constituye de tres elementos: (1) localidad, (2) ubicación, y (3) sentido de lugar" (Oslender 2002:111). La localidad es donde se desarrollan interacciones cotidianas, la ubicación es el ámbito geográfico, y el sentido de lugar representa esas formas en que los lugares son percibidos y apropiados por los sujetos en la vida social.

Desde este encuadre se comprende la localidad como espacio acuático, y el sentido de lugar a partir de la relación entre espacio e identidad que se articulan en los ríos (Oslender 1998). En esta misma dirección del sentido del lugar, este autor examina el Pacífico como una "geografía del terror", si bien subraya aspectos que incluyen la transformación en el sentido del lugar y los procesos de desterritorialización en el Pacífico. Esto como resultado de la violencia paramilitar y guerrillera en los comienzos del siglo XXI (Oslender 2008).

Para el caso del Valle del Patía, este espacio ha sido producido históricamente desde el cimarronaje. En esta línea, el investigador Francisco Zuluaga es quien más avanzó en la comprensión de la sociedad patiana desde el siglo XVIII, mediante el vínculo de este territorio en la época Colonial y Republicana con otros espacios y sociedades, no solo a partir de unas prácticas cimarronas, sino también a través de la presencia de patianos en los procesos independistas y en las guerras civiles, entre otros escenarios políticos (Zuluaga 1993).

El trabajo de este autor permite evidenciar la forma en que los patianos fueron construyendo territorialidad y resistencia en el Patía, por cuanto generaron "toda una cultura alrededor de su platanar donde se encontraba su mujer y sus hijos obteniendo los productos más indispensables para la subsistencia (...) estos platanares -pequeñas parcelas- se aglutinaban en veredas o caseríos con una intensa relación de parentesco" (Zuluaga 1992:98). En contraposición al Pacífico con los ciclos extractivos de tagua, platino y oro (Leal 2008), el patiano hizo de la ganadería no solo su principal actividad económica hasta hoy en día, sino uno de los ejes centrales a partir de los cuales sus prácticas socioculturales adquieren sentido (Zuluaga 1998).

El Valle del Patía, un espacio de bosque seco tropical diferente a las selvas lluviosas del Pacífico, fue convertido en un lugar ideal para el desarrollo de la ganadería; entre otras razones, porque para el patiano los pastos eran de "todos y de ninguno, soltaba sus reses a pastar y en la medida en que 'su' ganado se diseminaba por la llanura debió aprender el ejercicio de un permanente y extendido pastoreo sobre sus cabezas de ganado y las ajenas" (Zuluaga 1992:98). De hecho, hasta la década de 1940 la tradición oral afirmaba que todo era sitio. Es decir, un espacio abierto.

La historiadora Martha Herrera examina esto con base en las descripciones de Miguel de Santiesteban realizadas a mediados del siglo XVIII. Ella subraya que durante aquel siglo la mayor cobertura vegetal incidía en el verdor de las planicies, y que esto daba lugar al aumento de la pluviosidad (Herrera Ángel 2009). La narración que hace Santiesteban, "no sólo remite a la fertilidad de la tierra y a la abundante 
población libre que allí habitaba, sino también a formas distintas de percibir un mismo entorno y al problema del control de la mano de obra" (Herrera Ángel 2009:138). Asimismo, el imaginario colonial del entorno por parte de los hacendados y funcionarios coloniales hizo posible "el mantenimiento de formas de poblamiento y explotación de los recursos alternas, que no podían ser controladas por los sectores dominantes y, en esa medida, eran perseguidas con rigor" (Herrera Ángel 2009:138).

Esto configura un insumo investigativo para comprender el Patía desde la experiencia del cimarronaje, en la medida en que esta suerte de aislamiento geográfico también implicó la creación de una sociedad con valores diferentes a los establecidos por la sociedad blanca colonial. El cimarronaje, que se había inscrito en la vida cotidiana de los patianos, condujo a lo que Albán definió en un primer momento como "habitus cimarron"; esto es, un conjunto de prácticas culturales incorporadas por los patianos, que les permitieron vivir en libertad y resistencia frente al sistema esclavista (Albán 2004). El concepto de "habitus cimarron" "permite comprender cómo estas comunidades resistieron a los embates del sistema colonial, cómo se enfrentaron a él, de qué manera desarrollaron estrategias de supervivencia y cómo fueron creando una unidad social fuerte" (Albán 2004:7).

A la luz de los trabajos examinados el Patía articula elementos de la teoría social (historia regional y el concepto de "habitus" de Bourdieu) que nos permiten identificar que el territorio patiano ha sido un espacio de resistencia cultural. Sin embargo, Adolfo Albán, desde una perspectiva de la opción decolonial, le da un giro al concepto de "habitus cimarron" y conecta procesos de territorialización, festividades y gastronomía (del siglo XVIII y XX) desarrollados en el Patía y establece la categoría de "re-existencia". Esta noción supone comprender que los pueblos africanos no solo opusieron resistencia al poder dominante, sino que se reinventaron en la diferencia y subalternidad (Albán 2015), por cuanto "desarrollaron formas altamente creativas para continuar inventándose la existencia incluso por fuera de los marcos legales, pero también jugando con el sistema establecido" (Albán 2015:21).

La re-existencia en el Patía se destila en la vida cotidiana; por ejemplo, en la dimensión gastronómica, el bambuco patiano y la religiosidad, que representan experiencias articuladoras y estructurantes de las formas en que se ha imaginado, usado y construido del territorio patiano. Igualmente, en la medida en que implican modalidades de territorialización, las re-existencias se vinculan con relaciones de poder. Esto es, el poder lo ejerce quien ha usado, percibido y construido el territorio. A manera de caso, durante el trabajo de campo realizado en el Patía, compartiendo con uno de los vecinos de la vereda de Miraflores, notábamos que en sus recorridos cotidianos cuidaba las vacas hasta entrada la tarde, y al otro día, de madrugada, iba en su busca, repitiendo esta misma acción todos los días. No tardamos mucho en darnos cuenta de que en realidad lo que aquel vecino hacía era aprovechar la proximidad de una gran hacienda, la soledad del lugar y lo boscoso, para pasar a diario sus reses a los potreros del hacendado. De tal suerte que no solo aprovechaba los pastos y forrajes de esa propiedad, sino también las sales y mieles que estos hacendados compran para engordar sus novillos. Esta práctica configura una re-existencia en la medida que altera la relación de poder entre el patiano y el hacendado blanco/mestizo foráneo.

En geografía humana y antropología recientemente se han realizado esfuerzos sistemáticos por analizar los despojos asociados a la expoliación y extrahección minera, enfocándose en el Valle del Patía como espacio cultural (Melo Guzmán 2018; MosqueraVallejo 2020a). Estos trabajos identifican procesos de despojo ocurridos en el siglo XX y XXI en el Patía, y el nexo que tienen con dinámicas económicas, sociales y políticas a una escala regional. Además, se establecen las violencias y los desplazamientos de que han sido objeto los patianos como consecuencia de la minería ilegal (Melo Guzmán 2018; MosqueraVallejo y Paulsen-Espinoza 2020) y la ganadería extensiva desde mediados del siglo XX. Ambos trabajos permiten comprender de qué modo la extrahección minera configuraron ciertas zonas del Patía como una geografía del terror (Oslender 2008).

Igualmente, otro trabajo de geografía humana, pero esta vez desde la teoría de la escala, indaga acerca de los procesos de recuperación de tradiciones culturales en el Valle del Patía. En él el autor cuestiona el discurso de la invisibilidad (De Friedemann 1993) de los aportes de la gente negra a la construcción de la nación como totalidad globalizadora, y los reelabora como un proceso de producción de redes escalares; de tal suerte que estas "generan unas prácticas de visibilidad e invisibilidad geográfica, en donde la primera representaría el nexo y la difusión de los procesos culturales a otros territorios; mientras que la segunda simbolizaría una red conectada con proceso 
difundidos a nivel de la municipalidad, corregimiento o vereda" (Mosquera-Vallejo 2020b:260).

En este sentido, el trabajo de las agrupaciones culturales en el Patía, cuando eran reconocidas solo al nivel de los espacios rurales y por los mismos habitantes de la zona, representaba una visibilidad desde lo local, mientras que su práctica significaba una invisibilidad en el plano regional y nacional. En tanto las redes escalares van aumentando, el proceso de producción de escala hace que aquello que se percibe invisible, desde una escala nacional o global, se torne visible en la medida en que el proceso cultural, social, económico y político deja de hacerse pixel.

Como se puede apreciar en la síntesis de los trabajos descritos, ambos espacios permiten apreciar varios elementos que articulan las geografías, los entramados y los hibridismos. Frente a lo primero, es necesario reconocer que como ámbito geográfico el Valle del Patía corresponde a un bosque seco tropical. Ello supone no solo un espacio biofísico diferente, sino un proceso de apropiación y territorialización distinto, en la medida en que las plantas, animales, ríos que configuran el territorio patiano son diferentes a los del Pacífico (de bosque húmedo tropical y altísima pluviosidad). En ese sentido, los usos del territorio, actividades productivas, las categorías espaciales que cada sociedad produce, las percepciones construidas en estos dos espacios son distintos, independientemente de que sean territorios de poblaciones negras.

Desde la época Colonial las actividades económicas en el Valle del Patía fueron inicialmente los reales de minas, que luego se convertirían en haciendas ganaderas, según el Zuluaga (1993) una de las formas de territorialización del valle. Paralelo a esto, los negros libres y cimarrones harán de los platanares su primer espacio de territorialización. El Pacífico, en tanto, se fue poblando con la migración de otras gentes, y el trabajo en pequeños enclaves mineros distribuidos a lo largo de los ríos, donde "la extracción y el lavado de los minerales los realizan los esclavos negros" (Hoffmann 2007:54). En esta zona, la "territorialidad de la población rural está marcada por la historia de la migración y se caracteriza por un doble aspecto: el arraigo en un río o un caserío, donde se funda una familia y donde se desmonta un pedazo de tierra, conjugado por una fuerte movilidad de los hombres durante el transcurso del año" (Hoffmann 2007:57).

Todas estas formas de territorialidad se dan en medio de ciclos extractivistas que son una constante en el Pacífico nariñense. En el Valle del Patía, con su historia de cimarronaje, el despojo se va a configurar a partir de las haciendas ganaderas hasta hoy día, si bien en la actualidad el despojo y el narcotráfico han definido en estos espacios múltiples geografías del terror. La presencia de actores ilegales articulados con las actividades ilícitas del narcotráfico, la minería de oro y otras formas extractivas se ha intensificado en las últimas dos décadas en ambos espacios, ocasionando graves repercusiones a nivel social y ambiental. El desplazamiento, la fractura del tejido social, el asesinato de líderes sociales, la degradación de los tejidos de vida son algunas de sus consecuencias.

Otro aspecto relevante para comparar ambos espacios es lo referido a los efectos del artículo transitorio (A.T) 55 de la Constitución Política de 1991, y la posterior promulgación de la Ley 70 de 1993. Esta según Restrepo, es vista por los activistas negros como "el hito jurídico y político más importante del siglo XX, solo comparable con la abolición de la esclavitud a mediados del siglo XIX" (Restrepo 2013b:9), en tanto se trata de una realidad jurídicopolítica que planteó el reconocimiento de la gente negra como sujetos de inteligibilidad política, a partir de la etnización, y al mismo tiempo, recreó nuevos esquemas de representación de la negridad y de sus territorios. Para el caso del Valle del Patía destacaremos los consejos comunitarios; y para el Pacífico sur, el nexo entre biodiversidad y etnización, identificando de esta manera las formas en que el giro al multiculturalismo se articula en estos dos espacios.

Con esta nueva normativa política se reconocieron los derechos de las poblaciones negras. No obstante, el modelo de organización social y territorial en el que se inscribe la ley "Supone (...) la preexistencia de estructuras comunitarias -los consejos comunitarios que bastaría con reconocer y legitimar frente a los demás actores" (Hoffmann 2007:41). Esta opinión es compartida por otros investigadores de diferentes campos. Desde la investigación socio-jurídica se sostiene que "la Ley 70 resulta como proyección de la experiencia vivida por las poblaciones indígenas en el curso de las décadas de los setenta y ochenta del siglo pasado" (Romaña et al. 2010:122), por ende, el "Consejo Comunitario se asimila al Cabildo indígena, en tanto el territorio colectivo se funda a partir del modelo de resguardo" (Romaña et al. 2010:122). Una de las consecuencias de esto determinaría que el Consejo Comunitario adquiera "poco reconocimiento de las comunidades respecto a su papel y en consecuencia una baja gobernabilidad (Romaña et al. 2010:122).

Esta perspectiva destaca las dificultades que ha tenido la normativa para aplicarse en 
territorios concretos. Para el Valle del Patía, Adolfo Albán (comunicación personal, 2020) lo resume elocuentemente en un diálogo personal:

El Estado construye un modelo de organización de la gente negra para interlocutar. Y eso fue una cosa impuesta. Eso no existía, la gente no se pensaba así (...) Ahora, las comunidades negras se ven forzadas a organizarse de una manera que nunca se habían pensado, en un espacio donde el capitalismo empezó a ingresar a principios del siglo $\mathrm{XX}$, y definió de manera taxativa la propiedad privada y la delimitó entre los que tienen mucho y los que no tienen, y los intermedió por ahí (...) En ese contexto, cuando llega un modelo dem organización para la adquisición de la tierra con titulación colectiva, la gente asume que eso se debe comprar para repartirlo.

La baja gobernabilidad en los consejos comunitarios y la reticencia que genera en la gente la idea de territorio colectivo, por la cual los patianos entienden que lo colectivo hace referencia a la condición de las tierras como propiedad de todos, ha producido que varias de las fincas asignadas, adjudicadas y entregadas por el Estado colombiano hayan sido tomadas por algunos pobladores. Si bien esto ha permitido un mayor acceso a la tenencia de la tierra de gente negra, también ha desdibujado el sentido del consejo comunitario, pues muchos de los que se tomaron las fincas en realidad hicieron que miembros de su núcleo familiar adquirieran potreros, buscando así convertirse en los nuevos hacendados del Valle del Patía.

El discurso medioambiental es una de las ideas que más se consolidó con el giro hacia el multiculturalismo y la definición de la gente negra de ciertos territorios como grupo étnico, dado por el nexo entre etnización y biodiversidad. Y uno de los conceptos que en mayor medida ha articulado estos dos procesos ha sido el de territorio como espacio de vida. Concretamente, esta noción hace referencia a "todas aquellas condiciones naturales y sociales ligadas a un lugar determinado que posibilitan la existencia y desarrollo de las comunidades negras como grupo étnico con una tradición y cultura específicas" (Restrepo 2013b:228). Este modelo de territorio es imaginado como un espacio de vida, y sirve de sostén para que la gente negra del Pacífico sur sea concebida desde ciertos lugares de enunciación como ecologistas por naturaleza (Restrepo 2013b) o guardianes de la biodiversidad (Wade 2004).

Parte de las narrativas que articula el discurso medioambiental tiene que ver con que "el Pacífico también se piensa en términos de "corredores de vida', los modos viables de articulación entre las formas socioculturales de uso y el ambiente natural" (Escobar 2010:165). La descripción elaborada por Escobar -o alguna de las entrevistas que examina Restrepo para el Pacífico, precisamente con el fin de establecer el vínculo entre etnización y biodiversidad-, no existe en la bibliografía sobre el Valle del Patía, y al mismo tiempo, el discurso medioambiental en las imaginaciones políticas, espaciales e históricas, así como en los líderes negros, no se presenta con el mismo énfasis que en el Pacífico. Es decir, el Valle del Patía no es configurado a partir del imaginario verde.

Por lo tanto, la red de agentes sociales no son poderosas ONGs, el papel de la Iglesia católica es más reducido, y el CONPES, Consejo Nacional de Política Económica y Social, o algún otro tipo de política pública, nacional o internacional, desde la cual se configuren estas llanuras es inexistente. De esta forma, la descripción de ecólogos por naturaleza o guardianes de la biodiversidad, así como el modelo de territorio en espacio de vida, fue "desarrollado a partir de las prácticas territoriales y experiencias históricas propias de las áreas rurales del Pacífico colombiano. De ahí los impases[sic] para su aplicación en otros lugares del país como el Caribe continental o insular o los valles interandinos" (Restrepo 2013b:229).

Finalmente, la afirmación de este autor permite vincular, por un lado, el imaginario biodiverso del Pacífico como una experiencia singular, y por otro, el modelo de ocupación de territorio que articula trayectorias, improntas, imágenes diferentes a las de otros territorios de la negridad. Asimismo, los consejos comunitarios, copiados de la legislación indígena y de las experiencias del Pacífico, evidencian estas heterogeneidades, conflictividades las dificultades que conllevan los intentos de globalización y homogeneización realizados mediante la aplicación de modelos de territorio en espacios de la gente negra en Colombia.

\section{Reflexiones Finales}

Hemos examinado dos territorios de gente negra desde una serie de categorías, lo que ha derivado en 
una problemática que articula diferentes trayectorias históricas y espaciales en los dos ámbitos geográficos estudiados. En este sentido, los conceptos de identidad y diferencia (teoría antropológica), así como el de lugar (teoría de geografía humana), nos han servido de lentes a partir de los cuales se han leído estas dos zonas de estudio.

La descripción del Patía y el Pacífico sur en términos biofísicos permitió ver que mientras el primero responde a un tipo de ecosistema, el de bosque seco tropical -posiblemente el más alterado por acción antrópica en Colombia-; el otro es parte de una región denominada el Chocó biogeográfico. Un área destacada notablemente, al menos desde ciertas formaciones discursivas, en lo que respecta a zonas con mayor biodiversidad del planeta, por encima de las selvas del Amazonas, África Central y Occidental, y la India. Asimismo, se evidenció que en el proceso de formación histórica, las sociedades negras del Patía y del Pacífico sur presentan diferencias en la articulación con el Estado nacional. Frente al primer aspecto, no está de más destacar que una base geográfica y natural distinta supone la construcción de un modelo de naturaleza diferenciado. Para decirlo en otros términos, es probable que muchos habitantes del Valle del Patía no tengan idea acerca de los usos y significados que tiene la tagua o la piangua. Del mismo modo, posiblemente los negros del Pacífico sur no poseen las mismas destrezas como jinetes y manejando reses.

Aunque se haya buscado destacar diferencias de estos dos lugares en este trabajo, en el marco de la diferencia también hay articulaciones. Así, por ejemplo, la experiencia extractiva y la violencia constitutiva a la que han sido sometidos estos territorios han sido una constante desde la época Colonial hasta el neoliberalismo actual. Incluso parece que la violencia en estos territorios se ha hecho endémica. De hecho, luego de la firma del acuerdo de paz con la antigua guerrilla de las FARC-EP en Colombia, el corredor entre el Valle del Patía y el Pacífico sur es donde más han aumentado el asesinato de líderes sociales, las masacres y los desplazamientos forzados.

En este contexto, no se trata solo de lugares de encuentro (conflicto, articulación, intercambio) que se agencian desde la perspectiva de lo biodiverso, de los consejos comunitarios de comunidades negras, o de las re-existencias inscritas en la vida cotidiana, sino que también a través del terror (Oslender 2008).

Es decir, estos territorios aterrorizados lo son no solo en la medida en que su espacialidad es definida desde esta modalidad, sino porque esencialmente tanto el Valle del Patía como el Pacífico sur representan territorios del no-ser.

Finalmente, no hay que perder de vista que "en la zona del no-ser tenemos la guerra perpetua con momentos excepcionales de paz" (Grosfoguel 2012:96).

Agradecimientos: Nuestro especial agradecimiento a María Fernanda Anaya Chamorro por su ayuda en la elaboración de la cartografía temática, así como a los evaluadores anónimos asignados por la revista. Especialmente al revisor C, quien nos hizo los cuestionamientos que implicaron repensar muchos supuestos teóricos y metodológicos desde los cuales estábamos operando.

\section{Referencias Citadas}

Albán, A. 2004. La sociedad afropatiana: ¿habitus cimarrón y proyecto hegemónico anticolonial? Ponencia presentada en el Segundo Coloquio Nacional de Estudios Afrocolombianos. "Visualizando Nuevas Identidades, Territorios y Conocimientos". Universidad del Cauca, Popayán.

Albán, A. 2015. Sabor, Poder y Saber. Comida y Tiempo en los Valles Afroandinos del Patía y Chota-Mira. Editorial Universidad del Cauca, Popayán.

Almario García, O. 2009. De lo regional a lo local en el Pacífico sur colombiano, 1780-1930. HiSTOReLo Revista de Historia Regional y Local 1 (1):76-123.

Almario García, O. 2013. Modelos culturales en conflicto: grupos negros y misioneros agustinos en el Pacífico sur colombiano (1896-1954). Tabula Rasa (19):193-226.

Bhabha, H. 2002. El Lugar de la Cultura. Ediciones Manantial, Buenos Aires.
Escobar, A. 2000. El lugar de la naturaleza y la naturaleza dellugar: ¿Globalización o posdesarrollo? En La Colonialidad del Saber: Eurocentrismo y Ciencias Sociales: Perspectivas Latinoamericanas, compilado por Edgardo Lander. pp. 69-87. Clacso, Buenos Aires.

Escobar, A. 2003. Mundos y conocimientos de otro modo:el programa de investigación de modernidad/colonialidad Latinoamericano. Tabula Rasa (1):51-86.

Escobar, A. 2010. Territorios de Diferencia. Lugar, Movimientos, Vida, Redes. Traducido por E. Restrepo. Envión Editores, Popayán.

De Friedemann, N. 1993. Negros en Colombia: identidad e invisibilidad. América Negra 3:25-35.

Fernández, S. y A. Fernández 1992. Contribución al estudio florístico de la hoya hidrográfica del Patía. Novedades Colombianas. Nueva Época 5:27-44. 
Grosfoguel, R. 2012. El concepto de "racismo" en Michel Foucault y Frantz Fanon: ¿teorizar desde la zona del ser o desde la zona del no-ser? Tabula Rasa 16:79-102.

Haesbaert, R. 2011. Viviendo en el límite: los dilemas del hibridismo y de la multi/transterritorialidad. En Geografías Culturales: Aproximaciones, Intersecciones y Desafios, coordinado por P. Zusman, H. Castro y S. Adamo, pp. 49-76. Editorial de la Facultad de Filosofía y Letras Universidad de Buenos Aires, Buenos Aires.

Hall, S. 2003. ¿Quién necesita la identidad? En Cuestiones de Identidad Cultural, compilado por S. Hall y P. Du Gay, pp. 13-39. Amorrortu, Buenos Aires.

Herrera Ángel, M. 2009. Popayán: La Unidad de lo Diverso. Territorio, Población y Poblamiento en la Provincia de Popayán, Siglo XVIII. Uniandes, Ceso, Bogotá.

Hoffmann, O. 2007. Comunidades Negras en el Pacífico Colombiano. Innovaciones y Dinámicas Étnicas. Ediciones Abya-Yala, Quito.

Latour, B. 2008. Nunca Fuimos Modernos. Ensayo de Antropología Simétrica. Siglo XXI Editores, Buenos Aires.

Leal, C. 2008. Disputas por tagua y minas: recursos naturales y propiedad territorial en el Pacífico colombiano, 1870-1930. Revista Colombiana de Antropología 44 (2):409-438.

Leal, C. y E. Restrepo 2003. Unos Bosques Sembrados de Aserríos Historia de la Extracción Maderera en el Pacífico Colombiano. Colciencias - ICANH, Colección Clío, Convenio Universidad de Antioquia-Universidad Nacional de Colombia, Facultad de Ciencias Humanas y Económicas, Medellín.

Massey, D. 2004. Lugar, identidad y geografías de la responsabilidad en un mundo en proceso de globalización. Treballs de la Societat Catalana de Geografía 54:77-84.

Massey, D. 2012. Un sentido global del lugar. En Doreen Massey. Un Sentido Global del Lugar, compilado por A. Albet y N. Benach N, pp. 112-130. Icaria, Barcelona.

Melo Guzmán, J. 2018. Lavando el Oro del Patía: Conflicto, Despojo y Resistencia en la Comunidad Negra de El Hoyo (Cauca, Colombia). Tesis de Maestría, Departamento de Antropología, Universidad de Brasilia, Brasilia.

Moraes, R. 2014. Territorio en la Geografía de Milton Santos. Universidad Externado de Colombia, Bogotá.

Mosquera-Vallejo, Y. 2020a. Territorios de la negridad en Colombia: de las expoliaciones, extrahecciones a las re-existencias en el valle del Patía. Revista de Geografía Norte Grande 76:9-29.

Mosquera-Vallejo, Y. 2020b. Escala geográfica: visibilidades e invisibilidades en procesos culturales afrodescendientes (suroccidente de Colombia). Revista CS 30:251-276.

Mosquera-Vallejo, Y. y A. Paulsen-Espinoza 2020. Geografía del extractivismo: conflicto socioambiental en el río Sambingo. Reflexiones desde la ética ambiental. Estudios Socioterritoriales. Revista de Geografía 27:1-19.

Oslender, U. 1998. Espacio e identidad en el pacífico colombiano: perspectivas desde la costa caucana. Cuadernos de Geografía: Revista Colombiana de Geografía 7:251-290.
Oslender, U. 2002. Espacio, lugar y movimientos sociales: hacia una "espacialidad de resistencia". Scripta Nova. Revista electrónica de Geografía y Ciencias Sociales 6 (115). http:// www.ub.edu/geocrit/sn/sn-115.htm

Oslender, U. 2008. "Geografías del terror”: un marco de análisis para el estudio del terror. Scripta Nova. Revista Electrónica de Geografia y Ciencias Sociales, 12. https://revistes.ub.edu/index. $\mathrm{php} /$ ScriptaNova/article/view/1568

Restrepo, E. 2007. Identidades: planteamientos teóricos y sugerencias metodológicas para su estudio. Jangwa Pana 5 (1):24-35.

Restrepo, E. 2011. Modernidad y diferencia. Tabula Rasa 14:125-154.

Restrepo, E. 2013a. El giro a la biodiversidad en la imaginación del Pacífico colombiano. Revista Estudios del Pacífico Colombiano 1:171-199.

Restrepo, E. 2013b. Etnización de la Negridad: La Invención de las "Comunidades Negras" como Grupo Étnico. Editorial Universidad del Cauca, Popayán.

Restrepo, E. 2016. Espacialidades afrodescendientes en el Pacífico colombiano. En Territorios de Gente Negra: Procesos, Transformaciones y Adaptaciones: Ensayos sobre Colombia y Brasil, organizado por A. Rojas, A. Cardoso Simoes y F. Gomes, pp. 189-213. EDUFRB, Cruz das Almas.

Romaña, P.N., B.C. Geovo, Z.F. Paz y G.E. Banguero 2010. Titulación Colectiva para Comunidades Negras en Colombia. Espacio Creativo Imp., Bogotá.

Santos, M. 1994. O retorno do território. En Território, Globalização e Fragmentação, organizado por M. Santos, M.L. Silveira, M.A. De Souza, pp. 11-20. Editora HUCITEC y ANPUR, São Paulo.

Santos, M. 2000. La Naturaleza del Espacio: Técnica y Tiempo. Razón y Emoción. Ariel, Barcelona.

Velandia, P. y E. Restrepo, E. 2017. Estudios afrocolombianos: balance de un campo heterogéneo. Tabula Rasa 27:61-197.

Wade, P. 2002. Identidad. En Palabras para Desarmar, editado por M. Serje, M.C. Suaza y R. Pineda, pp. 255-264. Instituto Colombiano de Antropología e Historia, Bogotá.

Wade, P. 2004. Los guardianes del poder: biodiversidad y multiculturalidad en Colombia. En Conflicto e (In)Visibilidad: Retos en los Estudios de la Gente Negra en Colombia, compilado por E. Restrepo y A. Rojas, pp. 247-268. Editorial Universidad del Cauca, Popayán.

Zuluaga, F. 1992. La Sociedad Patiana de la segunda mitad del siglo XIX. Novedades Colombianas: Nueva Época 5:92-100.

Zuluaga, F. 1993. Guerrilla y Sociedad en el Patía. Editorial Facultad de Humanidades, Cali.

Zuluaga, F. 1998. Los hombres históricos del Patía o los héroes del tiempo encantado. En Geografía Humana de Colombia: Los Afrocolombianos, editado por J. Arocha Rodríguez, M. Dieck, N. Sánchez de Friedemann, O. Jiménez Meneses y C.M. Leal León, pp. 120-139. Instituto Colombiano de Antropología e Historia, Bogotá. 
